OPEN ACCESS

Edited by:

Ann Catrine Eldh,

Linköping University, Sweden

Reviewed by:

Sofi Sonesson,

Linköping University, Sweden

Jill Tirabassi,

University at Buffalo, United States

${ }^{*}$ Correspondence:

Lea Ettlin

xetl@zhaw.ch

Specialty section:

This article was submitted to Implementation Science,

a section of the journal

Frontiers in Health Services

Received: 18 August 2021 Accepted: 22 September 2021 Published: 16 November 2021

Citation:

Ettlin L, Rausch Osthoff A-K, Nast and Niedermann K (2021) Applicability of Exercise and Education

Programmes for Knee Osteoarthritis Management to Switzerland. Front. Health Serv. 1:760814. doi: 10.3389/frhs.2021.760814

\section{Applicability of Exercise and Education Programmes for Knee Osteoarthritis Management to Switzerland}

\author{
Lea Ettlin ${ }^{1,2 \star}$, Anne-Kathrin Rausch Osthoff ${ }^{1}$, Irina Nast ${ }^{1}$ and Karin Niedermann ${ }^{1}$ \\ ${ }^{1}$ Schools of Health Professions, Institute of Physiotherapy, Zurich University of Applied Sciences, Winterthur, Switzerland, \\ ${ }^{2}$ Department of Health Sciences and Health Policy, University of Lucerne, Lucerne, Switzerland
}

Objectives: The aim of this study was to assess the applicability of six OARSI (Osteoarthritis Research Society International) approved exercise and education programmes for the conservative management of knee osteoarthritis to the Swiss health care system.

Methods: The RE-AIM framework was used in this cross-sectional survey study to analyse the characteristics of the six exercise and education programmes. A survey was developed based on the RE-AIM dimensions, "Reach, Effectiveness, Adoption, Implementation, and Maintenance," for rating the applicability of the programmes (on a scale of $1=$ "least applicable" to $10=$ "most applicable"). Programme scores of $\geq 7$ indicated applicability to the Swiss health care system. Nine selected physiotherapy experts for knee OA management in Switzerland were invited for the rating.

Results: The six programmes were rated by six of the nine invited research experts with mean scores of between 5.9 and 9.45. Four programmes scored 7 or more. These four programmes all included supervised exercise sessions and education with the goal that the participants understand the diagnosis and the management of OA. The two lower rated programmes focused on exercise counselling or weight reduction.

Conclusion: The programme with the highest scores consists of exercise and education and scored higher than 7 in all RE-AIM dimensions. Therefore, this programme is most applicable to the Swiss health care system as only a few adaptations would be needed for its successful implementation.

Keywords: exercise and education programmes, implementation, knee osteoarthritis, RE-AIM, applicability

\section{INTRODUCTION}

The international clinical guidelines for the management of knee osteoarthritis $(\mathrm{OA})$, which were developed by the OA Research Society International (OARSI), American College of Rheumatology (ACR), and European Alliance of Associations for Rheumatology (EULAR), recommend exercise, education, and weight control, when appropriate, as first-line interventions (1-3). Pharmacological therapy or passive treatment might support first-line interventions (1-3). There is strong evidence that regularly performed exercises for knee OA have a positive effect on pain and joint function $(1-5)$. The long-term goal of these interventions is the enhancement of self-management in people 
with knee OA. However, clinical practise is often at variance with guidelines (6-10). Because of this, the OA guideline recommendations have already been translated into exercise and education programmes, or models of care, in several countries to make their application feasible and simplify implementation into clinical practise. There are six well-established, OARSI-endorsed programmes that meet the specific needs of their national health care systems $(9,10)$. These programmes have been successfully applied in real-world settings and have been proven effective (11).

According to national data, knee OA is the most common diagnosis in Swiss hospitals (12). However, both research and observation of clinical practise have shown that the guidelines recommendations are not being systematically applied in knee OA management and exercise and education appear to be underexploited in Switzerland, which results in an evidence-performance gap (13). In accordance with experience from other countries, the implementation of a national exercise and education programme in Switzerland would contribute to overcoming this evidence-performance gap (9, 10). Consequently, a network of physiotherapy experts for knee OA management was formed in 2019 to promote the implementation of an exercise and education programme, with a preference for one that was already established and approved by OARSI. The network included six researchers from three Universities of Applied Sciences in the three national language areas of Switzerland, i.e., German, French, and Italian, two clinical practitioners representing each of two different specialist physiotherapy societies, and one patient representative of the Swiss League Against Rheumatism (SLAR).

The implementation of a structured programme in a health care system is challenging and time-consuming $(9,10,14,15)$. For the successful implementation of a structured programme for knee OA, it must be aligned to the characteristics of the Swiss health care system and meet local needs. Switzerland's health care system is organised at the cantonal level and is decentralised, complex, and has a high level of local autonomy. This structure, along with the fee for service reimbursement (16), represent barriers to the implementation of new care structures and innovations (17). Many aspects (e.g., programme characteristics, provider characteristics, community factors, and health care system structures) influence the implementation process and need to be considered carefully (18). This has proven to be the case for other disease management programmes, such as diabetes (17). An implementation into the Swiss health system requires not only an analysis of the clinical effectiveness of the programme, but also an assessment of the necessary national adaptations. However, Rodriguez and Bernal (19) have stated that in the implementation of evidence-based treatment, the more cultural adaptations of an innovation are made, the higher the risk of compromising the effectiveness of the treatment, i.e., essential components linked to positive outcomes are changed and may compromise the effectiveness of the treatment $(20,21)$. Therefore, the process for selecting a programme applicable to Switzerland should be: 1 . Identification of the programme that best meets the needs and requirements of the Swiss health care system, and 2. Application of the rule "The less adaptations, the better."
The aim of this study was to analyse the six OARSIapproved exercise and education programmes, using the RE-AIM framework, to assess their applicability for implementation in the Swiss health care system.

\section{METHODS}

\section{Design}

This cross-sectional survey study was based on a secondary analysis of the six OARSI-approved exercise and education programmes, using the RE-AIM framework (15) to rate the applicability of the programmes for implementation in Switzerland.

\section{Participants}

All members of the above-mentioned network of experts in knee OA management were invited to participate in the survey and to rate the applicability of the programmes. They were personally informed of the survey and invited to participate by email, with the survey (Word-document) attached. A follow-up reminder was sent 2 weeks later.

For transparency and consistency of reporting in implementation studies, this study follows the "Standards for Reporting Implementation studies" (StaRI) statement.

\section{Characteristics of the OARSI-Approved Programmes}

The six OARSI-approved programmes are: 1. "Osteoarthritis Chronic Care Program (OACCP) Australia," 2. "Better management of patients with osteoarthritis (BOA) Sweden," 3. "Good Life with Osteoarthritis in Denmark (GLA:D $\left.{ }^{\circledR}\right)$," 4. "Osteoarthritis Healthy Weight For Life (OA HWFL) Australia," 5. "Amsterdam osteoarthritis cohort (AMSOA) of The Netherlands," and 6. "Joint Implementation of Osteoarthritis guidelines in the West Midlands" (JIGSAW). The characteristics of the six programmes, evaluated using the RE-AIM dimensions, regarding target population, interventions, duration, primary outcomes, number of patients enrolled, and reimbursement, were extracted from published studies, reports, and the websites of the respective programmes. Table 1 displays a short overview of the programmes, showing the aim of the programme, how many people were enrolled, and how the local reimbursement system was organised.

\section{Use of Framework for Programme Analysis}

The RE-AIM framework was used to analyse the Reach, Effectiveness, Adoption, Implementation, and Maintenance of the six programmes (42). Briefly described, "the reach dimension of the framework refers to the percentage and characteristics of individuals receiving the intervention; effectiveness refers to the impact of the intervention, including anticipated as well as unanticipated outcomes; adoption concerns the percentage and representativeness of settings that adopt the intervention; implementation refers to the consistency and cost of delivering the intervention; and maintenance refers to longterm sustainability at both the setting and individual levels" (43). 
TABLE 1 | Overview of exercise and education programmes.

\begin{tabular}{|c|c|c|c|c|}
\hline Programme & Country of origin & $\begin{array}{l}\text { Aim of programme (published on their } \\
\text { website, if available) }\end{array}$ & $\begin{array}{l}\text { Number of patients } \\
\text { enrolled }\end{array}$ & Reimbursement policies \\
\hline $\mathrm{BOA}(8,10,22-24)$ & Sweden & $\begin{array}{l}\text { All patients with OA in Sweden should be } \\
\text { offered adequate information and exercise } \\
\text { according to the guidelines }\end{array}$ & $\begin{array}{l}\text { Approx. 10,941 } \\
\text { patients/year } \\
(2008-2020)\end{array}$ & $\begin{array}{l}\text { Coverage by universal healthcare: } \\
\text { 100\% coverage with a limited } \\
\text { out-of-pocket spending (maximum fee of } \\
\sim 120 \text { USD for outpatient visits during a } \\
\text { 12-month period) }\end{array}$ \\
\hline OACCP (25-28) & Australia & $\begin{array}{l}\text { A pathway to improved care is offered for } \\
\text { people who have one of the most } \\
\text { common, debilitating, costly and rapidly } \\
\text { growing chronic conditions-OA }\end{array}$ & $\begin{array}{l}\text { Approx. 1,250 } \\
\text { patients/year } \\
(2012-2020)\end{array}$ & $\begin{array}{l}\text { Coverage by universal healthcare } \\
\text { (Medicare): } \\
\text { Subsidies of supervised exercise sessions } \\
\text { and consultations (assessments) } \\
\text { according to management plan with a } \\
\text { possible rebate from the private health } \\
\text { insurers. Providers set the cost of the } \\
\text { program }\end{array}$ \\
\hline $\mathrm{GLA} \mathrm{D}^{\circledR}(7,29,30)$ & Denmark & $\begin{array}{l}\text { Implementation of current clinical } \\
\text { guidelines for OA into clinical care. } \\
\text { Evidence-based treatment plan for OA, } \\
\text { consisting of patient education and } \\
\text { neuromuscular exercise }\end{array}$ & $\begin{array}{l}\text { Approx. 10,000 } \\
\text { patients/year in } \\
\text { Denmark (2013-2020) }\end{array}$ & $\begin{array}{l}\text { Coverage by universal healthcare: } \\
100 \% \text { reimbursement when referred by an } \\
\text { orthopaedic surgeon; } 40 \% \text { coverage when } \\
\text { referred by a general practitioner; } 0 \% \\
\text { when self-referred (patient must pay all } \\
\text { costs) }\end{array}$ \\
\hline OA HWFL (31-34) & Australia & $\begin{array}{l}\text { Improvement of daily living and associated } \\
\text { quality of life by reducing knee and hip } \\
\text { pain and stiffness and improving mobility. } \\
\text { Furthermore, improvement of preparation } \\
\text { (pre-hab) for knee or hip replacement } \\
\text { surgery (if relevant). }\end{array}$ & $\begin{array}{l}\text { Approx. 1,125 } \\
\text { patients/year } \\
(2008-2016)\end{array}$ & $\begin{array}{l}\text { Coverage by universal healthcare: } \\
100 \% \text { of programme costs if participants } \\
\text { eligible (i.e., over } 548 \text { USD worth of } \\
\text { products, service and support, provided } \\
\text { for free) }\end{array}$ \\
\hline AMSOA (35-38) & The Netherlands & $\begin{array}{l}\text { Collection of data (AMS-OA cohort): } \\
\text { Provision of insight into the relation } \\
\text { between clinical characteristics and } \\
\text { functional outcome of patients with hip or } \\
\text { knee OA. }\end{array}$ & $\begin{array}{l}\text { Approx. } 82 \\
\text { patients/year } \\
(2009-2017)\end{array}$ & $\begin{array}{l}\text { Coverage by universal healthcare: } \\
\text { Full, partial, or no coverage (according to } \\
\text { the health care policy and supplementary } \\
\text { insurance) }\end{array}$ \\
\hline JIGSAW (39-41) & United Kingdom (EU) & $\begin{array}{l}\text { Primary care support: } \\
\text { - addressing the unmet needs of adults } \\
\text { with OA, through the provision of } \\
\text { innovations } \\
\text { - systematic implementation of } \\
\text { International Guidelines and Quality } \\
\text { Standards for OA at practise level } \\
\text { across European sites }\end{array}$ & $\begin{array}{l}\text { Primary Care in Clinical } \\
\text { Commissioning Groups } \\
\text { (CCGs) UK. } 3 \text { groups, } \\
\sim 100 \text { practises }\end{array}$ & $\begin{array}{l}\text { Coverage by universal healthcare: } \\
100 \% \text { by the National Health Service } \\
\text { (NHS). } \\
\text { European Institute of Innovation \& } \\
\text { Technology (EIT)-Health funded Joint } \\
\text { Implementation of osteoarthritis Guidelines } \\
\text { in Western Europe (JIGSAW-E). } \\
\text { Implementation of this funded model was } \\
\text { being tested in the Netherlands, Norway, } \\
\text { Denmark and Portugal. }\end{array}$ \\
\hline
\end{tabular}

OA, Osteoarthritis; Approx., Approximately.

The dimensions manifest themselves at various implementation levels (individual, organisation, community) and can facilitate the investigation of the impact of a programme on public health in a specific health care system (44). The RE-AIM dimensions were used to develop a survey to rate the applicability of each programme to the Swiss health care system. Glasgow et al. (15) stated that, "The use of the RE-AIM metrics might not result in a clearcut decision, but it will facilitate the more informed and comprehensive consideration of all the relevant factors and make explicit the values and priorities" (42). The REAIM website (www.re-aim.org) defines a score of 9-10 as "excellent," 7-8 as "good, but needs a little work," 5-6 as "fair, needs additional attention," and $<5$ as "poor, needs serious attention."

\section{Development of Survey}

The questions in the survey were based on the key pragmatic planning questions for RE-AIM formulated by Glasgow and Estabrooks (44). They were further developed for the survey to rate the applicability of the six chosen programmes for implementation in Switzerland (44). The original RE-AIM questions were used as headings for each dimension. The context of the programmes in each dimension was explained in a short text and the developed questions posed to rate the applicability. These questions are displayed in Table 2.

For each of these programme characteristics, the RE-AIM dimensions were rated on a Likert scale from 0 (not applicable at all) to 10 (very applicable). The programmes were anonymized, and their characteristics presented in a random sequence to prevent programme identification. 
TABLE 2 | Individual RE-AIM characteristics with the guiding questions for the analysis of the six programmes.

\begin{tabular}{|c|c|c|c|c|c|}
\hline $\begin{array}{l}\text { BOA }(8,22,23) \text {, } \\
\text { Sweden }\end{array}$ & $\begin{array}{l}\text { OACCP (25-27), } \\
\text { Australia }\end{array}$ & $\begin{array}{l}\text { GLA:D }{ }^{\circledR}(7,29) \text {, } \\
\text { Denmark }\end{array}$ & $\begin{array}{l}\text { OA HWFL (web-based } \\
\text { program) (31-33), } \\
\text { Australia }\end{array}$ & $\begin{array}{l}\text { AMSOA (35-37), The } \\
\text { Netherlands }\end{array}$ & $\begin{array}{l}\text { JIGSAW (39), } \\
\text { United Kingdom }\end{array}$ \\
\hline
\end{tabular}

"Reach"-Who is intended to benefit and who actually participates in the intervention?

Symptoms of hip, knee, Diagnosed knee or hip OA Symptoms of, or diagnosed Overweight (BMI $\geq 28$ ) Diagnosed hip or knee OA; GP consultation because of or hand $O A$ (referred or with pain $\geq 4 / 10$ (referred) hip or knee OA (referred or patients with diagnosed $\geq 18$ years; non-traumatic hip, knee, hand, foot OA, self-referred) Self-referred) (supported by $X$-Ray) hip pain and joint pain; $\geq 45$ years and knee OA, for pre-rehab

"Effectiveness"-What are the most important benefits (primary outcomes) you are trying to achieve and what is the likelihood of negative outcomes?

Pain, physical function, Pain, physical function, Pain, physical function, PA, Weight loss, improved Pain, physical function, Uptake of Quality Indicators PA, Q willingness for surgery, QoL and of NICE guidelines. self-efficacy. length of stay after surgery. Physical performance,

Fear-avoidance behaviour self-efficacy. Use of

and reported sick leave. painkillers, reported instability. 
exercise and patient education. OA HWFL only included patients with knee OA and/or knee pain and a BMI > 28, with the focus mainly on support for weight management. JIGSAW was the only programme that had no exercise sessions included, giving only advice on exercise and physical activity.

Dimension "Effectiveness": the impact of individualised exercise and education on pain, function and quality of life was assessed for all programmes with follow-up and showed a significant effect in all those outcomes. JIGSAW, which had no follow-up, improved the patient pathway by applying the National Institute for Health and Care Excellence (NICE) guideline recommendations.

Dimension "Adoption": all programmes were well-established in their country of origin, and some in other countries also. BOA, OACCP, GLA:D ${ }^{\circledR}$, AMSOA, and JIGSAW were offered in outpatient settings, such as clinics, care or rehabilitation centres, and clinical practises. OACCP was provided in hospitals and outpatient clinics, AMSOA in a rehabilitation centre, and OA HWFL in an online and phone-based setting. Both AMSOA and OACCP combined numerous health care professions in multidisciplinary teams, whilst the other programmes only involved two to three health care professions.

Dimension "Implementation": the programmes were similar in their content (e.g., support for self-management, patient education, and exercise) and in the minimal duration of the programmes, but their exercise programmes differed in intensity and the opportunity to prolong. The duration of the programmes was normally a minimum of 6 weeks and maximum of 3 months. The OACCP and OA-HWFL programmes from Australia offered additional longer-term support when necessary. The programmes varied in their approaches, but, at a minimum, all programmes included consultation or educational sessions, together with recommendations on exercises or an exercise programme. The structure of the JIGSAW programme was different and focused on the first consultation in primary care and on patient education. JIGSAW, a consultation model, included an additional four sessions of patient education, but with no follow-up measures for patients. The supervised and home-based exercise programmes accorded with international guidelines but were applied with different concepts.

Dimension "Maintenance": The follow-ups to measure the outcomes of the patients were assessed after completion of the exercise sessions and a few months after the end of the programme. The operationalisation of the programmes was analysed on the system level. All programmes showed a nationwide roll-out and, therefore, good "Adoption" by the target population (which influences "Maintenance"). AMSOA was the only exception, since the programme remained wellestablished only in the rehabilitation centre where it was originally developed. The six programmes were initiated between 2008 and 2013 and are all ongoing.

\section{Rating of Applicability}

Six of the nine network members invited to participate $(66.7 \%)$ returned their ratings. The clinical practitioners representing two different specialist physiotherapy societies and a representative of a German universality of applied Sciences did not respond.
Figure 1 displays the mean scores of the ratings on the RE-AIM dimensions for each programme. The means scores across the six programmes ranged between 5.9 and 9.4. The overall mean scores of each programme and the range of the mean scores of dimensions were: GLAD 9.4 (8.2-9.7), AMSOA 7.9 (7.0-8.7), BOA 7.8 (6.3-9.3), OACCP 7.0 (5.8-7.5), JIGSAW 6.3 (4.8-6.5), and OA HWFL 5.9 (2.7-8.2).

\section{DISCUSSION}

The comparative analysis and rating of the six programmes, following the RE-AIM framework, found that the GLA:D ${ }^{\circledR}$ programme would be the most applicable to the Swiss health care system. The result suggests that GLA:D ${ }^{\circledR}$ could be implemented successfully in Switzerland with only few adaptations.

\section{Implementation Considerations}

The ratings provide guidance for planning both the implementation strategy and the activities on the different dimensions. Through consideration of the respective levels, the results of this rating assist in deciding which dimensions need more attention during the development of the implementation strategy and activities. For example, combining the locations (where) and the health care professionals involved (who) resulted in the lowest scores in "Adoption" for all programmes. In the complex and decentralised Swiss health care system, together with the high autonomy of the health care professions, an innovation would have a better chance of successful implementation when only a few key stakeholders were involved in the programme. Furthermore, an evidence-performance gap is present in the conservative management of knee OA, thus the programme is intended to be offered in the outpatient setting. GLA:D ${ }^{\circledR}$ is offered mainly in outpatient settings and only involves a few stakeholders. Therefore, the programme reached a relatively high score of 8.2 , meaning "good, but needs a little work."

So, the team implementing GLA:D ${ }^{\circledR}$ would need to pay extra attention to "Adoption" during the implementation process. "Adoption" is associated with the leading indicators of acceptability, appropriateness, and feasibility (45). The implementation activities should, therefore, focus on those leading indicators and involve important stakeholders to maximise scores in "Adoption." The standardisation of the outcome measures and reporting could improve interdisciplinary work between referring doctors and physiotherapists. However, OACCP stated that it was essential that all the health care professionals involved were convinced that the programme enhances conservative management (10).

In the other four dimensions, i.e., Reach, Effectiveness, Implementation, and Maintenance, GLA:D ${ }^{\circledR}$ showed a mean score of 9.5 or higher, which is defined as "excellent." These dimensions would require fewer adaptations and need less attention during the implementation process. This means that targeting patients with knee OA or knee pain, with no further inclusion or exclusion criteria, seems to be a good option, according to the rating. Other programmes reached lower scores because they set an age limit, or only include referred patients, or 


\section{Rating of the RE-AIM dimensions for each programme}

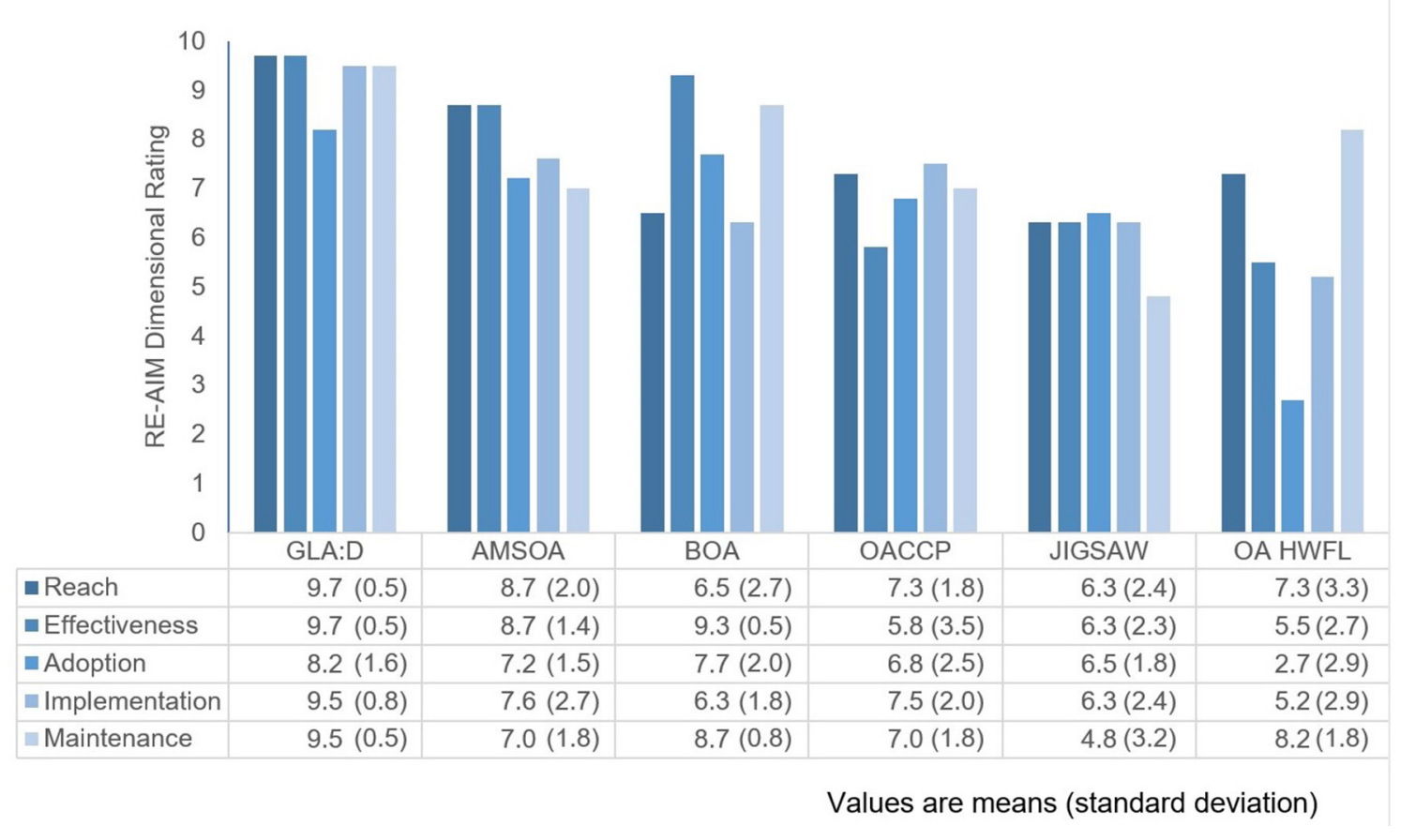

FIGURE 1 | Ratings of the RE-AIM dimensions for each programme.

overweight patients with a $\mathrm{BMI} \geq 28$. High scores for GLA:D ${ }^{\circledR}$ also resulted from its main focus being on the symptoms of knee OA, physical function, and the behaviour of the patients (in terms of fear-avoidance behaviour or sick leave). The additional factors in other programmes (e.g., willingness for surgery, weight control, nutrition), which are not intended to be included in the primary outcomes of a Swiss programme, might have resulted in lower programme scores. Regarding the content, the four programmes BOA, AMSOA, GLAD, and OACCP provide exercise sessions with supervision. Individualised and supervised exercise is applied to ensure sufficient load and progression and to support quality of performance for longterm self-management (46). Supervised exercise may improve adherence and may also lead to better outcomes (22). GLA:D ${ }^{\circledR}$ integrates neuromuscular exercises (NEMEX), i.e., functional knee stability, during the exercises. NEMEX have been proven to be safe and effective $(32,46)$. Sensomotor control and functional stability should be supervised by a physiotherapist, because the quality of performance, i.e., in NEMEX, is crucial (46). The four programmes combine supervised with home-based exercises for best results (46). The high score (9.5) of GLA:D ${ }^{\circledR}$ for "Implementation," with a difference of almost 2 compared to the other programme scores, indicates that the duration of 8 weeks, or 12 sessions, and the integration of NEMEX might be wellaccepted by all parties, i.e., patients, providers, and insurers. In contrast, the costs of online treatments, or a longer duration, e.g., OA HWFL, might not be fully covered by Swiss insurers. High scores for "Maintenance" were reached in programmes with follow-ups at 3 and 12 months, together with the strategy for a nationwide rollout with no referral needed for participation. This seems to be the "Maintenance" strategy most compatible with the intended goals of a Swiss programme.

\section{Additional Offers for Improving Conservative Management}

This analysis and the ratings show that also the lower scoring programmes, i.e., all the programmes except GLA:D ${ }^{\circledR}$, have some important aspects that impact the implementation goals in Switzerland.

\section{Online Programme}

After the initial implementation of a programme, some other aspects need to be considered for potential inclusion, e.g., in times of a global pandemic, an online programme has the advantage that patients can perform the exercises whenever, or wherever, they want. BOA provides an additional web-based version, named "Joint Academy" (47). Although direct support from a physiotherapist showing how to perform the exercises would be lacking, some patients might prefer an online programme. Joint Academy offers online support from a physiotherapist for 6 weeks duration. Personalised exercises are delivered by email and supported by videos and take-home messages. Although an online exercise programme might not be supported financially by Swiss healthcare insurers, patients may choose to pay themselves for this type of offer. 


\section{Weight Management}

OA HWFL, which focused on weight reduction and nutrition, achieved lower scores for applicability for implementation in the Swiss health care system in most RE-Aim-dimensions. However, the working collaboration of referring medical doctors, physiotherapists, and nutritionists helped to improve knee OA management (48). Overweight is a risk factor in developing knee $\mathrm{OA}$ and has a negative impact on the course of this chronic disease. Weight reduction improves knee pain and function (49, 50). Weight management could, therefore, be beneficial and should be considered when the population shows many cases of knee OA correlating to overweight or obesity. This additional intervention, ideally complementary to an exercise and education programme, also has the potential to improve knee OA management (31).

\section{Written Information}

The JIGSAW programme had the lowest mean score over all dimensions for applicability for implementation in the Swiss health care system, compared to the other programmes. Although patient education is included in the exercise and education programmes of, e.g., GLA: ${ }^{\circledR}, B O A$, or AMSOA, a written booklet elaborating the most important information on OA could further support patient self-management or motivate them to join an exercise and education programme.

\section{Strengths and Limitations}

A strength of this study is the use of the RE-AIM dimensions to analyse and rate the chosen programmes to ascertain which would be most applicable for implementation in Switzerland, and to indicate potential challenges to the implementation process. A limitation of this analysis could be selection bias, since the information provided in the survey was the only information on the programmes that was either published in English or available on the respective websites. Another limitation may be that the non-responders included the two different specialist physiotherapy societies could therefore lead to underrepresentation of clinical practitioners, even though there was still one participant who is a researcher but also working in clinical practise. The underrepresentation could result in a lack of the opinions or perspectives of people who are specialised in the practical application of a programme, especially, on the feasibility of the contents, (i.e., dimension implementation) or the practicability of the programme when there are many different health care professionals included (i.e., dimension adoption). However, this study focused on the representatives

\section{REFERENCES}

1. McAlindon TE, Bannuru RR, Sullivan MC, Arden NK, Berenbaum F, Bierma-Zeinstra SM, et al. OARSI guidelines for the non-surgical management of knee osteoarthritis. Osteoarthritis Cartilage. (2014) 22:36388. doi: 10.1016/j.joca.2014.01.003

2. Fernandes L, Hagen KB, Bijlsma JWJ, Andreassen O, Christensen P, Conaghan PG, et al. EULAR recommendations for the non-pharmacological core management of hip and knee osteoarthritis. Ann Rheum Dis. (2013) 72:112535. doi: 10.1136/annrheumdis-2012-202745 of the main providers of such a programme in Switzerland, i.e., physiotherapists, who are important stakeholders in the future implementation of an exercise and education programme for the management of knee OA.

In Switzerland, there is a need for a structured and systematic programme for patients with knee OA, due to the high prevalence of the disease and the lack of knowledge of the beneficial effects of exercise and education. A renowned and established programme might be favourably accepted and contribute to closing the existing evidence-performance gap in clinical practise. Furthermore, such a programme would represent an improvement in non-surgical and nonpharmacological management and follow-up. In conclusion, the GLA:D ${ }^{\circledR}$ programme with the highest scores has already been implemented in other countries. The programme consists of exercise and education and scored higher than 7 in all RE-AIM dimensions. Therefore, this programme is most applicable to the Swiss health care system as only few adaptations would be needed for its successful implementation in Switzerland.

\section{DATA AVAILABILITY STATEMENT}

The raw data supporting the conclusions of this article will be made available by the authors, without undue reservation.

\section{ETHICS STATEMENT}

This study did not fall within the scope of the Swiss Human Research Act and authorisation from an Ethics Committee was not required. Raters were informed that by participation in the survey they automatically provided their informed consent and that their ratings were used in an anonymised manner.

\section{AUTHOR CONTRIBUTIONS}

$\mathrm{LE}$ and $\mathrm{KN}$ were contributing to conception and design of the study. LE collected and analysed the programme information and data of the ratings. $\mathrm{KN}$ contributed to the drafting and revision of the manuscript. All authors have read and approved the manuscript.

\section{ACKNOWLEDGMENTS}

The authors give their thanks to the knee OA experts in Switzerland for their participation. Moreover, a cordial thanks is owed to Karen Linwood for the correction of the English text.
3. Hochberg MC, Altman RD, April KT, Benkhalti M, Guyatt G, McGowan J, et al. American College of Rheumatology 2012 recommendations for the use of nonpharmacologic and pharmacologic therapies in osteoarthritis of the hand, hip, and knee. Arthritis Care Res. (2012) 64:465-74. doi: 10.1002/acr.21596

4. Imoto AM, Pardo JP, Brosseau L, Taki J, Desjardins B, Thevenot O, et al. Evidence synthesis of types and intensity of therapeutic land-based exercises to reduce pain in individuals with knee osteoarthritis. Rheumatol Int. (2019) 39:1159-79. doi: 10.1007/s00296-019-04289-6

5. Fransen $M$, McConnell S, Harmer AR, Van der Esch M, Simic M, Bennell KL. Exercise for osteoarthritis of the knee. Cochrane 
Database Syst Rev. (2015) 1:CD004376. doi: 10.1002/14651858.CD0043 76.pub3

6. Li CS, Karlsson J, Winemaker M, Sancheti P, Bhandari M. Orthopedic surgeons feel that there is a treatment gap in management of early OA: international survey. Knee Surg Sports Traumatol Arthrosc. (2014) 22:36378. doi: 10.1007/s00167-013-2529-5

7. Skou ST, Roos EM. Good Life with osteoArthritis in Denmark (GLA:D $\left.\AA^{T M}\right)$ : evidence-based education and supervised neuromuscular exercise delivered by certified physiotherapists nationwide. BMC Musculoskelet Disord. (2017) 18:72. doi: 10.1186/s12891-017-1439-y

8. Thorstensson CA, Garellick G, Rystedt H, Dahlberg LE. Better management of patients with osteoarthritis: development and nationwide implementation of an evidence-based supported osteoarthritis self-management programme. Musculoskeletal Care. (2015) 13:67-75. doi: 10.1002/msc.1085

9. Dziedzic KS, Allen KD. Challenges and controversies of complex interventions in osteoarthritis management: recognizing inappropriate and discordant care. Rheumatology. (2018) 57(Suppl. 4):iv88-98. doi: 10.1093/rheumatology/key062

10. Allen KD, Choong PF, Davis AM, Dowsey MM, Dziedzic KS, Emery C, et al. Osteoarthritis: models for appropriate care across the disease continuum. Best Pract Res Clin Rheumatol. (2016) 30:503-35. doi: 10.1016/j.berh.2016.09.003

11. Eyles JP, Hunter DJ, Bennell KL, Dziedzic KS, Hinman RS, van der Esch M, et al. Priorities for the effective implementation of osteoarthritis management programs: an OARSI international consensus exercise. Osteoarthritis Cartilage. (2019) 27:1270-9. doi: 10.1016/j.joca.2019.02.704

12. Swiss Federal Statistical Office. Gesundheitsstatistik (2014). Available online at: https://www.bfs.admin.ch/bfs/fr/home/statistiques/sante.assetdetail.349483. html (accessed February 1, 2021).

13. Ettlin L, Nast I, Huber EO, Niedermann K. Does the conservative non-pharmacological management of knee osteoarthritis in Switzerland reflect the clinical guidelines? A survey among general practitioners, rheumatologists, and orthopaedic surgeons. Front Rehabilit Sci. (2021) 2:658831. doi: $10.3389 /$ fresc.2021.658831

14. Kirchner JE, Smith JL, Powell BJ, Waltz TJ, Proctor EK. Getting a clinical innovation into practice: an introduction to implementation strategies. Psychiatry Res. (2020) 283:112467. doi: 10.1016/j.psychres.2019.06.042

15. Glasgow RE, Harden SM, Gaglio B, Rabin B, Smith ML, Porter GC, et al. RE-AIM planning and evaluation framework: adapting to new science and practice with a 20-year review. Front Public Health. (2019) 7:64. doi: 10.3389/fpubh.2019.00064

16. OECD. Health at a Glance 2017: OECD Indicators. Paris: OECD Publishing (2017). Available online at: https://www.oecd-ilibrary.org/social-issuesmigration-health/health-at-a-glance-2017_health_glance-2017-en (accessed May 25, 2021).

17. Lauvergeon S, Mettler D, Burnand B, Peytremann-Bridevaux I. Convergences and divergences of diabetic patients' and healthcare professionals' opinions of care: a qualitative study. Health Expect. (2015) 18:111-23. doi: 10.1111/hex.12013

18. Durlak JA, DuPre EP. Implementation matters: a review of research on the in?uence of implementation on program outcomes and the factors affecting implementation. Am J Community Psychol. (2008) 24:32750. doi: 10.1007/s10464-008-9165-0

19. Domenech Rodriguez MM, Bernal G. Cultural Adaptations: Tools for Evidence-Based Practice with Diverse Populations. Washington, DC: American Psychological Association. (2012).

20. Domenech Rodríguez MM, Bernal G. Bridging the gap between research and practice in a multicultural world. In: Bernal G, Domenech Rodríguez MM, editors. Cultural Adaptations: Tools for Evidence-Based Practice With Diverse Populations. Washington, DC: American Psychological Association (2012). p. 265-87. doi: 10.1037/13752-013

21. Bernal G, Domenech Rodríguez MM. Cultural adaptation in context: psychotherapy as a historical account of adaptations. In: Bernal G, Domenech Rodríguez MM, editors. Cultural Adaptations: Tools for Evidence-Based Practice with Diverse Populations. Washington, DC: American Psychological Association (2012). p. 3-22. doi: 10.1037/13752-001

22. Dell'Isola A, Jönsson T, ranstam J, Dahlberg LE, Hansson EE. Education, home exercise, and supervised exercise for people with hip and knee osteoarthritis as part of a nationwide implementation program: data from the better management of patients with osteoarthritis registry. Arthritis Care Res. (2020) 72:201-7. doi: 10.1002/acr.24033

23. Jönsson T, Ekvall Hansson E, Thorstensson CA, Eek F, Bergman P, Dahlberg LE. The effect of education and supervised exercise on physical activity, pain, quality of life and self-efficacy - an intervention study with a reference group. BMC Musculoskelet Disord. (2018) 19:198. doi: 10.1186/s12891-0182098-3

24. BOA-registret (2021). Available online at: https://boa.registercentrum.se/boain-english/better-management- of-patients-with-osteoarthritis-boa/p/By_ o8GxVg (accessed June 3, 2021).

25. Teoh LSG, Eyles JP, Makovey J, Williams M, Kwoh CK, Hunter DJ. Observational study of the impact of an individualized multidisciplinary chronic care program for hip and knee osteoarthritis treatment on willingness for surgery. Int J Rheum Dis. (2017) 20:1383-92. doi: 10.1111/1756-185X.12950

26. Eyles JP, Mills K, Lucas BR, Williams MJ, Makovey J, Teoh L, et al. Can we predict those with osteoarthritis who will worsen following a chronic disease management program? Arthritis Care Res. (2016) 68:126877. doi: $10.1002 /$ acr.22836

27. Claes B-EA, Leung HWC, Matters K, Williams MJ, Hunter DJ. Interim analysis: an interdisciplinary team approach in facilitating weight reduction and improving function for people with knee or hip osteoarthritis. the osteoarthritis chronic care program at royal north shore hospital. Nutr Dietet. (2015) 72:232-9. doi: 10.1111/1747-0080.12166

28. Agency for Clinical Innovation (ACI). Osteoarthritis Chronic Care Program Model of Care. (2020). Available online at: https://aci.health.nsw.gov. au/resources/musculoskeletal/osteoarthritis_chronic_care_program/ osteoarthritis-chronic-care-program (accessed June 3, 2021).

29. Skou ST, Pedersen BK, Abbott JH, Patterson B, Barton C. Physical activity and exercise therapy benefit more than just symptoms and impairments in people with hip and knee osteoarthritis. J Orthop Sports Phys Ther. (2018) 48:439-47. doi: 10.2519/jospt.2018.7877

30. GLA:D International (2021). Available online at: https://gladinternational. org/ (accessed June 3, 2021).

31. Atukorala I, Makovey J, Lawler L, Messier SP, Bennell K, Hunter DJ. Is there a dose-response relationship between weight loss and symptom improvement in persons with knee osteoarthritis? Arthritis Care Res. (2016) 68:110614. doi: $10.1002 /$ acr.22805

32. McGill B, O'Hara BJ, Grunseit AC, Bauman A, Lawler L, Phongsavan P. Healthy weight for life programme: evaluating the practice and effectiveness of a weight loss maintenance programme in the private health insurance setting. SAGE Open Med. (2019) 7:2050312119873814. doi: 10.1177/2050312119873814

33. Makovey J, Lawler L, Bennell KL, Hunter DJ. Dose response relationship between weight loss and improvement in quality of life in persons with symptomatic knee osteoarthritis. Osteoarthritis Cartilage. (2015) 23:A386. doi: 10.1016/j.joca.2015.02.713

34. OAHWFL (2021). Available online at: https://healthyweightforlife.com.au/ osteoarthritis-hwfl/ (accessed June 3, 2021).

35. Knoop J, Leeden $M$ van der, Esch $M$ van der, Thorstensson CA, Gerritsen $\mathrm{M}$, Voorneman RE, et al. Association of lower muscle strength with self-reported knee instability in osteoarthritis of the knee: results from the Amsterdam Osteoarthritis Cohort. Arthritis Care Res. (2012) 64:3845. doi: 10.1002/acr.20597

36. Knoop J, Dekker J, van der leeden M, Van der Esch M, Thorstensson CA, Gerritsen M, et al. Knee joint stabilization therapy in patients with osteoarthritis of the knee: a randomized, controlled trial. Osteoarthrit Cartil. (2013) 21:1025-34. doi: 10.1016/j.joca.2013.02.310

37. Sanchez-Ramirez DC, van der leeden, van der esch, Roorda, verschueren, dieen, et al. Increased knee muscle strength is associated with decreased activity limitations in established knee osteoarthritis: two-year follow-up study in the Amsterdam osteoarthritis cohort. J Rehabil Med. (2015) 47:64754. doi: 10.2340/16501977-1973

38. Amsterdam-Osteoarthritis (AMS-OA) cohort. ResearchGate. Available online at: https://www.researchgate.net/project/Amsterdam-OsteoarthritisAMS-OA-cohort (accessed June 3, 2021).

39. Schiphof D, Vlieland TPV, van Ingen R, Peter WF, Meesters JJ, de Wit MP, et al. Joint implementation of guidelines for osteoarthritis in Western Europe: 
JIGSAW-E in progress in The Netherlands. Osteoarthritis Cartilage. (2017) 25:414. doi: 10.1016/j.joca.2017.02.714

40. Hay E, Dziedzic K, Foster N, Peat G. Optimal Primary Care Management of Clinical Osteoarthritis and Joint Pain in Older People: A Mixed-Methods Programme of Systematic Reviews, Observational and Qualitative Studies, and Randomised Controlled Trials. Southampton: NIHR Journals Library (2018). p. 294. doi: 10.3310/pgfar06040

41. WMAHSN (2020). Available online at: https://www.wmahsn.org/ programmes/view/joint-implementation-of-guidelines-for-osteoarthritisoa-in-western-europe-jigsaw-e (accessed June 3, 2021).

42. Glasgow RE, Klesges L M, Dzewaltowski DA, Estabrooks PE, Vogt TM. Evaluating the impact of health promotion programs: using the RE-AIM framework to form summary measures for decision making involving complex issues. Health Educ Res. (2006) 21:688-94. doi: 10.1093/her/cyl081

43. King DK, Glasgow RE, Leeman-Castillo B. Reaiming RE-AIM: using the model to plan, implement, and evaluate the effects of environmental change approaches to enhancing population health. Am J Public Health. (2010) 100:2076-84. doi: 10.2105/AJPH.2009.190959

44. Glasgow RE, Estabrooks PE. Pragmatic applications of RE-AIM for health care initiatives in community and clinical settings. Prev Chronic Dis. (2018) 15:E02. doi: 10.5888/pcd15.170271

45. Weiner BJ, Lewis CC, Stanick C, Powell BJ, Dorsey CN, Clary AS, et al. Psychometric assessment of three newly developed implementation outcome measures. Implement Sci. (2017) 12:108. doi: 10.1186/s13012-017-0635-3

46. Ageberg E, Roos EM. Neuromuscular exercise as treatment of degenerative knee disease. Exerc Sport Sci Rev. (2015) 43:14-22. doi: 10.1249/JES.0000000000000030

47. Dahlberg LE, Grahn D, Dahlberg JE, Thorstensson CA. A web-based platform for patients with osteoarthritis of the hip and knee: a pilot study. JMIR Res Protoc. (2016) 5:e115. doi: 10.2196/resprot.5665

48. Hunter DJ, Hinman RS, Bowden JL, Egerton T, Briggs AM, Bunker SJ, et al. Effectiveness of a new model of primary care management on knee pain and function in patients with knee osteoarthritis: Protocol for THE PARTNER STUDY. BMC Musculoskelet Disord. (2018) 19:132. doi: 10.1186/s12891-018-2048-0

49. Gandhi R, Wasserstein D, Razak F, Davey JR, Mahomed NN. BMI independently predicts younger age at hip and knee replacement. Obesity. (2010) 18:2362-6. doi: 10.1038/oby.2010.72

50. Midgley J. An evidence review of osteoarthritis, with focus on the obese - considering conservative management, multi-morbidity, surgery and the implications of restricted access to knee or hip replacement because of weight. Int J Orthop Trauma Nurs. (2020) 40:100840. doi: 10.1016/j.ijotn.2020.100840

Conflict of Interest: $\mathrm{KN}$ is a member of the network of experts in physiotherapy for knee OA management. However, $\mathrm{KN}$ did not participate in the survey and the ratings.

The remaining authors declare that the research was conducted in the absence of any commercial or financial relationships that could be construed as a potential conflict of interest.

Publisher's Note: All claims expressed in this article are solely those of the authors and do not necessarily represent those of their affiliated organizations, or those of the publisher, the editors and the reviewers. Any product that may be evaluated in this article, or claim that may be made by its manufacturer, is not guaranteed or endorsed by the publisher.

Copyright (C) 2021 Ettlin, Rausch Osthoff, Nast and Niedermann. This is an openaccess article distributed under the terms of the Creative Commons Attribution License (CC BY). The use, distribution or reproduction in other forums is permitted, provided the original author(s) and the copyright owner(s) are credited and that the original publication in this journal is cited, in accordance with accepted academic practice. No use, distribution or reproduction is permitted which does not comply with these terms. 